FERREIRA, E.F. et al. Utilização de subprodutos do babaçu na nutrição animal. PUBVET, Londrina, V. 5, N. 22, Ed. 169, Art. 1139, 2011.

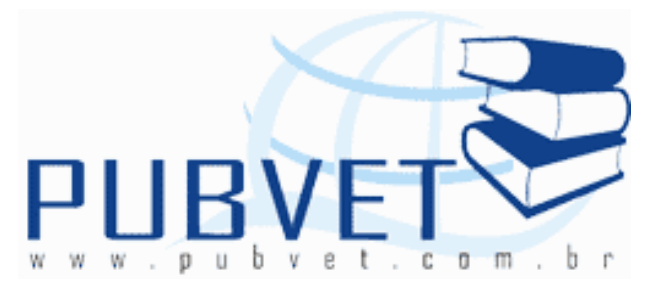

PUBVET, Publicações em Medicina Veterinária e Zootecnia.

\title{
Utilização de subprodutos do babaçu na nutrição animal
}

Edvaldo Francisco Ferreira ${ }^{1}$; Layla Sousa de Castro $^{1}$; Michele Moreira Martins de Oliveira²; Tercya Lúcidi de Araújo Silva²; Daniel Noal Moro²

${ }^{1}$ Acadêmico do Curso de Zootecnia da Faculdade de Imperatriz (FACIMP), email: edvaldoitz@hotmail.com

${ }^{2}$ Professores da Faculdade de Imperatriz (FACIMP). Av. Prudente de Morais, s/no, Qd. 1 a 6 - Residencial Kubitscheck CEP. 65900-000.

\section{Resumo}

Objetivou-se realizar uma revisão sobre os subprodutos derivados do babaçu (na forma de torta e farelo) que são utilizados como substitutos de alimentos tradicionais em rações de animais de interesse zootécnicos, onde foi possível comprovar sua eficácia quando utilizados em níveis adequados na ração, pois na maioria dos trabalhos analisados não houve comprometimento no desempenho, rendimento de carcaça e nem na produtividade dos animais, sendo uma boa opção como alimento alternativo, já que a alimentação é um dos fatores que mais limitam a criação de animais devido o alto custo.

Palavras-chave: Alimento alternativo, ração, desempenho, produtividade, custo, animais. 
FERREIRA, E.F. et al. Utilização de subprodutos do babaçu na nutrição animal. PUBVET, Londrina, V. 5, N. 22, Ed. 169, Art. 1139, 2011.

\section{Use of babassu products in animal nutrition}

\section{Abstract}

The objective was to perform a review of the derived products from babassu (in the form of cake and meal) that are used as substitutes for traditional foods in diets of livestock animals of interest, where it was possible to prove its effectiveness when used at appropriate levels in the diet, because most of the studies analyzed there was no compromising on performance, carcass yield and productivity of animals or being a good option as alternative food, since food is one of the factors that limit breeding because of the high cost.

Keywords: Alternative food, feed, performance, productivity, cost, animals.

\section{INTRODUÇÃO}

O Babaçu (Orbygnia speciosa) é uma palmeira encontrada no Brasil em quantidade considerável nos estados do Maranhão, Piauí, Ceará, Tocantins e Bahia. O estado do Maranhão é o principal produtor de amêndoas de babaçu, participando com $94,70 \%$ da produção nacional que em 2007 foi de 114.874 toneladas (IBGE, 2007).

É a palmeira mais utilizada na indústria extrativista brasileira e considerada a mais rica do ponto de vista econômico, devido a mesma apresentar inúmeras utilidades, dentre elas ingredientes para ração, na forma de torta e farelo, podendo ser utilizada como alimento alternativo na nutrição animal, no período de escassez de ingredientes tradicionais e ou preços elevados de matérias primas tradicionais.

A criação de animais apresenta alguns fatores limitantes, dos quais se pode citar a alimentação que representa até $70 \%$ dos custos de uma criação. Pensando em minimizar estes custos a utilização de alimentos alternativos, gerados em grande quantidade pelas indústrias de processamento de alimentos, como substitutos de ingredientes tradicionais como o milho e o farelo de soja nas rações, pode ser uma solução, pois na maioria das vezes 
FERREIRA, E.F. et al. Utilização de subprodutos do babaçu na nutrição animal. PUBVET, Londrina, V. 5, N. 22, Ed. 169, Art. 1139, 2011.

apresentam alto valor nutritivo, além de favorecer a diminuição dos impactos ambientais que os mesmos podem causar.

O Brasil vem se destacando nas exportações de carne, ocupando o primeiro lugar como exportador de carne bovina e de frango, e o quarto em carne suína e a tendência é de um crescimento ainda maior na produção, devido a investimentos e utilização de tecnologias, melhoramento genético, melhorias na alimentação, sanidade e manejo. E com isso vem à necessidade de maiores quantidades de matéria-prima para formulação de rações, para que o país continue produzindo em quantidade e qualidade atendendo o mercado nacional e internacional e se manter competitivo, há a preocupação da origem dos ingredientes que serão utilizados e que os mesmos não se tornem competitivos com aqueles que fazem parte da alimentação humana.

Diante desta problemática os nutricionistas tornam-se peças chaves, pois é um desafio para eles encontrar alimentos que substituam ingredientes tradicionais, pois esses substitutos devem apresentar características físicoquímicas e valor biológico que satisfaçam as exigências nutricionais dos animais, sem no entanto comprometer o desempenho e a produtividade dos mesmos, para isso deve-se levar em consideração os fatores nutricionais e os anti-nutricionais que ocorrem nas matérias primas empregadas na fabricação de rações animais já que cada espécie animal apresentam particularidades morfofisiológicas que diferenciam os níveis de nutrientes requeridos.

Pelo exposto pretende-se realizar uma revisão sobre utilização dos subprodutos do babaçu como alimentos alternativos na nutrição animal.

\section{REVISÃO DE LITERATURA}

A produção industrial de aves e suínos teve um enorme avanço nos últimos anos e conseqüentemente importância significativa na economia do país, devido ao conhecimento do ingrediente das rações e as exigências nutricionais dos animais, levando em consideração as diferentes fases produtivas, além de melhorias de manejo e ambiência, toda essa preocupação se deve ao objetivo principal que seria o aumento da produtividade de aves e 
FERREIRA, E.F. et al. Utilização de subprodutos do babaçu na nutrição animal. PUBVET, Londrina, V. 5, N. 22, Ed. 169, Art. 1139, 2011.

suínos, visando melhorar o desempenho utilizando mais eficientemente as rações, alimentos tradicionais e alternativos (ROSTAGNO et al., 2007).

O Babaçu pertence à família Palmae, tem origem brasileira na região Amazônica e Mata Atlântica na Bahia. A palmeira de babaçu chega a alcançar 20 metros de altura, aproveitados da raiz às folhas. Dela se extrai a matériaprima utilizada na fabricação de margarinas, sabões e cosméticos. O broto dessa palmeira fornece palmito de boa qualidade e o fruto, enquanto verde, serve para defumar a borracha, quando maduro, sua parte externa é comestível (PAVLAK et al., 2007). Da amêndoa pode-se obter rações, ácidos graxos e glicerinas (SOLER et al., 2007). O esmagamento do coco babaçu produz dois tipos de óleos: um para fins comestíveis e outro para fins industriais (óleo láurico) este possui características excelentes para produção de biodiesel. A utilização do óleo de babaçu para fins comestíveis tem sofrido declínio constante, em virtude de duas razões: a substituição por óleos mais acessíveis, e a tendência dos consumidores a optarem por óleos e gorduras não saturadas (HERRMANN et al., 2001; LIMA et al., 2007).

SOLER et al. (2007) afirmam que a composição física do fruto indica quatro partes aproveitáveis: epicarpo (11\%), mesocarpo $(23 \%)$, endocarpo (59\%) e amêndoa (7\%). A amêndoa corresponde de 6 a $8 \%$ do peso do coco integral. As amêndoas pesam, em média, de 3 a 4 g, e contêm entre 60 a 68\% de óleo, podendo alcançar $72 \%$ em condições mais favoráveis de crescimento da palmeira.

Da extração do óleo por pressão mecânica resulta a torta de babaçu, que deve apresentar a seguinte composição: umidade máxima de $12 \%$, proteína máxima de $20 \%$, gordura residual máximo de $12 \%$ e cinzas de no máximo $6 \%$. Já o farelo de babaçu é o resultado da extração do óleo por meio de solvente químico, apresentando as seguintes características: umidade máxima de $12 \%$, teor de proteína mínimo de 19\%, gordura residual máximo de 3\% e cinzas máximo de $6 \%$ estas são as exigências para que o babaçu Orbignia oleifera burrat seja comercializado e utilizado na alimentação animal (BRASIL, 1975). 
FERREIRA, E.F. et al. Utilização de subprodutos do babaçu na nutrição animal. PUBVET, Londrina, V. 5, N. 22, Ed. 169, Art. 1139, 2011.

PASCOAL (2006) comenta que o farelo de babaçu é pouco utilizado na alimentação animal, em relação aos farelos produzidos no Brasil, devido a sua variação bromatológica, além de ser produzido em pequena escala, sendo sua utilização mais significativa nas regiões norte e nordeste por serem as maiores produtores do fruto (babaçu). O farelo de babaçu apresentou em sua composição bromatológica os seguintes ingredientes com suas respectivas percentagens: matéria seca 92,57\%; proteína bruta 20,36\%; energia digestível $2.057 \mathrm{Kcal} / \mathrm{Kg}$; estrato etéreo 13,7\%; fibra bruta 19,19\%; fibra em detergente neutro 64,50\%, fibra em detergente ácido 38,44\%; cálcio 0,70\% (CAVALCANTE et al., 2005).

A torta de babaçu vem sendo utilizada em ruminantes como suplemento protéico, principalmente em bovinos de leite, promovendo aumento no teor de gordura do leite produzido, porém a sua utilização em não ruminantes é pouco conhecida, principalmente quando se fala em frango de corte industrial e até mesmo aves caipiras melhoradas (ANDRIGUETO, 1999; SILVA, 2009). A sua utilização em animais não ruminantes, o mesmo autor faz restrição ao seu uso sendo recomendadas pequenas quantidades para os suínos, não devendo ultrapassar o nível máximo de $7 \%$ para aves como ingrediente da ração (ANDRIGUETO, 1999).

\subsection{Utilização em animais ruminantes}

Em experimento realizado com vacas mestiças em lactação substituindo farelo de trigo por torta de babaçu na cidade de Iguatu, na região Centro Sul do Estado do Ceará, a dieta com $100 \%$ de substituição do farelo de trigo pela torta de babaçu apresentou menor custo com alimentação quando comparada com a dieta sem torta de babaçu, porém, ao nível de $75 \%$ de substituição obteve-se melhor relação custo-benefício, em relação à dieta sem torta de babaçu, foi observado também que a substituição supriu as necessidades de mantença e produção dos animais estudados, (SILVA, 2006).

A avaliação do desempenho e digestibilidade de nutrientes em ovinos sem raça definida alimentados com rações contendo farelo de babaçu 
FERREIRA, E.F. et al. Utilização de subprodutos do babaçu na nutrição animal. PUBVET, Londrina, V. 5, N. 22, Ed. 169, Art. 1139, 2011.

comprovou efeito linear decrescente $(P<0,05)$ da inclusão do farelo de babaçu sobre o peso vivo final, o peso vivo ao abate, o ganho de peso total e o ganho de peso diário, pois para cada $10 \%$ de participação do farelo de babaçu na dieta, houve redução de $51,4 \mathrm{~g} /$ dia no ganho de peso dos animais. Esse resultado é explicado pela redução na ingestão de matéria seca, que limitou a ingestão de energia e proteína, além de outros nutrientes. Por outro lado, não foi observada influência dos níveis de farelo de babaçu sobre a conversão alimentar, que apresentou média de 8,01 (XENOFONTE et al., 2008).

Em contrapartida os coeficientes de digestibilidade da matéria seca, matéria orgânica, proteína bruta e extrato etéreo aumentaram linearmente $(P<0,05)$ de acordo com os níveis de farelo de babaçu. Essa resposta está associada à redução na ingestão desses nutrientes pelos animais, resultando em maior tempo de permanência desse material no trato gastrintestinal, favorecendo a digestibilidade. Os níveis de farelo de babaçu não influenciaram a digestibilidade da fibra em detergente neutro, embora o consumo dessa fração também tenha reduzido, provavelmente em virtude da maior variação na digestibilidade desse componente.

Já em pesquisa com ovinos Santa Inês em confinamento a substituição parcial do farelo de soja e milho por farelo de babaçu com dietas contendo $20 \%$ não interferiu nas características da carcaça dos animais (SOUSA JUNIOR, 2003).

\subsection{Utilização em animais não ruminantes}

Observou-se em trabalho realizado com frango de corte utilizando farelo de babaçu que não houve nenhuma alteração no desempenho e no rendimento de carcaça e que a avaliação econômica para utilização deste alimento foi viável quando utilizado na ração dos frangos com idade de 21 aos 42 dias com inclusão de $6 \%$ deste ingrediente na ração, (CARNEIRO et al., 2009), entretanto é necessário levar em consideração o custo do milho e farelo de soja, pois o preço pode interferir na escolha da matéria-prima para rações, sendo mais viável a utilização de farelo de babaçu quando os preços dos 
FERREIRA, E.F. et al. Utilização de subprodutos do babaçu na nutrição animal. PUBVET, Londrina, V. 5, N. 22, Ed. 169, Art. 1139, 2011.

ingredientes tradicionais tiverem com custo elevado, porém devido os subprodutos do babaçu serem encontrados durante todo o ano em locais onde predomina as florestas de cocais, como Maranhão, Piauí e Tocantins, o farelo torna uma fonte alternativa para frango de corte em fase final de crescimento sem comprometer os índices zootécnicos dos animais. No entanto, mais estudos são necessários avaliando as características de carcaça, tanto em relação ao rendimento quanto em relação à qualidade.

SILVA (2009) afirma que frangos caipira "Label Rouge " podem ser alimentados com a torta de babaçu a $32 \%$ a partir dos 35 dias de idade sem comprometer o rendimento de carcaça, gordura abdominal, deposição de lipídeos e proteínas nas carcaças, sem haver diferença estatisticamente significativa $(P>0,05)$ entre os valores de lipídios e proteínas encontrados nas carcaças em função do aumento dos níveis de inclusão da torta $(8,16,24$ e $32 \%)$. O que acontece é que os frangos caipiras são abatidos mais tardiamente e conseqüentemente eles acabam se tornando mais aptos para digerir a torta de babaçu por essa ser rica em fibra bruta conforme já mencionado anteriormente.

Na piscicultura também já verificou-se o uso de farelo de babaçu em dietas para tambaqui, onde não foi observada influência $(P>0,05)$ do farelo de babaçu sobre o desempenho produtivo, rendimento de carcaça e filé dos juvenis de tambaqui, em inclusão de até $12 \%$ de farelo de babaçu, não afetando o consumo de ração, nem comprometendo de forma negativa o ganho de peso dos peixes e nem nas características de composição da carcaça. No entanto os autores fazem uma observação para que seja dada maior atenção à condição hepática dos animais, principalmente se o alimento for utilizado para peixes mais jovens, por períodos mais longos ou em percentuais mais elevados em ralação aos testados (6 e 12\%). Já que houve diminuição do índice hepatossomático, esta alteração pode está relacionada às reservas de energia presentes no fígado que seriam usadas para compensar alguma perda energética, ou mesmo em resposta à ação de algum fator antinutricional presente no ingrediente (LOPES et al., 2010). 
FERREIRA, E.F. et al. Utilização de subprodutos do babaçu na nutrição animal. PUBVET, Londrina, V. 5, N. 22, Ed. 169, Art. 1139, 2011.

Em trabalho realizado para comprovar efeitos tóxicos de alimentos alternativos para abelhas Apis mellifera, onde tal efeito foi mensurado através do índice de mortalidade e do tempo médio de mortalidade das abelhas confinadas onde as mesmas receberam alimentação controlada, o farelo de babaçu não se mostrou tóxico, resultado semelhante ocorreu com o feno de leucena, o feno de mandioca, a farinha de vagem de algaroba e o sucedâneo de leite para bezerros, já que houve aumento da longevidade das abelhas, dessa forma tais alimentos podem ser utilizados na formulação de rações protéicas principalmente nos períodos de escassez de alimentos tradicionais (PEREIRA et al., 2007).

\section{CONSIDERAÇÕES FINAIS}

Os subprodutos do babaçu utilizados na nutrição animal (torta e farelo) contribuem de forma significativa como alimento alternativo, pois em vários trabalhos onde foi feito a substituição de ingredientes tradicionais não houve perdas de produtividade.

A inclusão de subprodutos de babaçu pode ser uma alternativa para minimizar o custo das rações tanto de animais não ruminantes como de animais ruminantes.

Mais trabalhos científicos devem ser realizados para se ter melhores conclusões a respeito das matérias primas à base de babaçu.

Ainda não existem trabalhos que façam análise sensorial de carcaças de animais alimentados com essas matérias primas.

\section{REFERÊNCIAS BIBLIOGRÁFICAS}

ANDRIgUetTo, J. M.; PERLY, L.; MINARDI, Í., et al. A. Nutrição animal: As bases e os fundamentos da nutrição animal - Os alimentos. Nobel, São Paulo, 1999.

BRASIL. Especificações para a padronização, classificação e comercialização interna do óleo, da torta e do farelo de babaçu Orbignia oleifera Burrat. Ministério da Agricultura, 1975.

CARNEIRO, A. P. M.; PASCOAL, L. A. F.; WATANABE, P. H., et al. Farelo de babaçu em rações para frangos de corte na fase final: desempenho, rendimento de carcaça e avaliação econômica. Ciência Animal Brasileira. Goiânia, v. 10, n. 1, p. 40-47, 2009. 
CAVALCANTE, R. R.; FIgUEIRÊDO, A. V.; CARVALHO, M. A. M., et al. Digestibilidade aparente de nutrientes de rações balanceadas com alimentos alternativos para cutias (Dasyprocta prymnolopha) em crescimento. Ciência Animal Brasileira v. 6, n. 3, p. 163-171, 2005.

HERRMANN, I.; NASSAR, A. M.; MARINO, M. K., et al. Coordenação no SAG do Babaçu: Exploração Racional Possível?. Anais do III Congresso Internacional de Economia e Gestão de Negócios Agroalimentares - FEARP/USP, 2001.

IBGE - INTITUTO BRASILEIRO DE GEOGRAFIA E ESTATÍSTICA. Produção da Extração Vegetal e da Silvicultura 2007.

LIMA, J. R. O.; SILVA, R. B.; SILVA, C. C. M., et al. Biodiesel de babaçu (Orbignya sp.) obtido por via etanólica. Química Nova. v. 30, n.3. São Paulo, 2007.

LOPES, J. M.; PASCOAL, L. A. F.; SILVA FILHO, F. P., et al. Farelo de babaçu em dietas para tambaqui. Revista Brasileira de Saúde e Produção Animal. v. 11, n.2, p. 519-526. 2010.

PASCOAL, L. A. F.; BEZERRA, A. P. A.; GONÇALVES, J. S. Farelo de babaçu: valor nutritivo e utilização na alimentação animal. Revista Eletrônica Nutritime, v.3, n. 4, p.339-345, 2006.

PAVLAK, M. C. M.; ZUNIGA, A. D.; LIMA, T. L. A., et al. Aproveitamento da farinha do mesocarpo do babaçu (Orbignya martiana) para obtenção de etanol. Evidência, Joaçaba, v. 7, n. 1, p. 7-24. 2007.

PEREIRA, F. M.; FREITAS, B. M.; VIEIRA NETO, J. M., et al. Efeito tóxico de alimentos alternativos para abelhas Apis mellifera. Ciência Rural. Santa Maria, v. 37, n. 2, p. 533-538, 2007.

ROSTAGNO, H. S.; BÜNZEN, S.; SAKOMURA, N. K.; et al. Avanços metodológicos na avaliação de alimentos e de exigências nutricionais para aves e suínos. Revista Brasileira de Zootecnia. vol. 36 suppl.0 Viçosa, 2007.

SILVA, Rubens Fausto. Avaliação nutricional da torta de babaçu para frangos de corte Label Rouge: Desempenho e características de carcaça de 36 a 84 dias de idade. 2009. Universidade Federal de Goiás.

SILVA, Teresa Cristina da Paixão. Substituição do Farelo de Trigo pela Torta de Babaçu na Alimentação de Vacas Mestiças em Lactação. 2006. Dissertação, Universidade Federal Rural de Pernambuco - PE.

SOLER, M. P.; VITALI, A. A.; MUTO, E. F. Tecnologia de quebra do coco babaçu (Orbignya speciosa). Ciência e Tecnologia de Alimentos. Campinas, p. 717-722. 2007.

SOUSA JUNIOR, Antônio de. Substituição parcial do farelo de soja e milho por farelo de babaçu na terminação de ovinos. Dissertação. Universidade Federal do Piauí. 2003.

XENOFONTE, A. R. B.; CARVALHO, F. F. R.; BATISTA, A. M. V., et al. Desempenho e digestibilidade de nutrientes em ovinos alimentados com rações contendo farelo de babaçu. Revista Brasileira de Zootecnia. v.37, n.11, Viçosa, 2008. 